\title{
On the Moral Considerability of Homo sapiens and Other Species
}

\author{
RONALD SANDLER
}

Assistant Professor of Philosophy

Department of Philosophy and Religion

Northeastern University

371 Holmes Hall, Boston, MA 02115-5000, USA

Email:r.sandler@neu.edu

\section{JUDITH CRANE}

Assistant Professor of Philosophy

Department of Philosophy

Southern Illinois University Edwardsville

Box 1433, Edwardsville, IL 62026, USA

Email:jcrane@siue.edu

\begin{abstract}
It is sometimes claimed that as members of the species Homo sapiens we have a responsibility to promote the good of Homo sapiens itself (distinct from the good of its individual members). Lawrence Johnson has recently defended this claim as part of his approach to resolving the problem of future generations. We show that there are several difficulties with Johnson's argument, many of which are likely to attend any attempt to establish the moral considerability of Homo sapiens or species generally. Further, even if Homo sapiens were morally considerable, this would not ground an adequate response to the problem of future generations. The sort of moral considerability that would be appropriate to Homo sapiens, or species generally, would not be as robust nor have the implications that many have supposed.
\end{abstract}

\section{KEY WORDS}

Species, moral considerability, interests, future generations, Homo sapiens 


\section{RONALD SANDLER AND JUDITH CRANE}

It is a popular claim that we have a responsibility to promote the interests of our species. The content of this claim is ambiguous between: (1) We, as members of the species Homo sapiens, have a responsibility to promote the good of other individual members of the species; and (2) We, as members of the species Homo sapiens, have a responsibility to promote the good of Homo sapiens itself (distinct from the good of its individual members). A recent defence of (2) has been presented by Lawrence Johnson (2003) as part of his approach to resolving the problem of future generations (justifying moral concern for indeterminate human beings that constitute future generations). ${ }^{1}$ Johnson believes that 'we cannot base a call for respect for future generations on an ethic concerned only with individual humans. We can have an ethic of respect for future generations on the basis of a recognition that humanity is a morally considerable entity - or not at all' (485).

This paper is principally concerned with the claim that species, including Homo sapiens, are entities with morally considerable interests over and above any interests of the organisms that comprise them. We argue that there are several difficulties with Johnson's argument, many of which are likely to attend any attempt to establish the moral considerability of Homo sapiens or species generally. We further argue that even if Homo sapiens were morally considerable, this would not ground an adequate response to the problem of future generations. The sort of moral considerability that would be appropriate to Homo sapiens (and other species) would not be as robust and would not have the implications that many might suppose.

\section{JOHNSON'S ARGUMENT}

Johnson's argument for the moral considerability of Homo sapiens proceeds in three stages. The first stage is intended to establish that Homo sapiens has interests. The second stage is intended to establish that we ought to have moral concern for those interests. The third stage is intended to show that moral concern for the interests of Homo sapiens will ground concern for future generations. ${ }^{2}$

\section{Stage One}

1. '...a species is not a collection, but a spatiotemporally located individual' (478).

2. 'A species is, moreover, a living entity' (478).

3. 'A living entity is an ongoing process' (478).

4. Therefore a species is an ongoing life-process (from 1, 2, 3).

5. 'A living entity has an interest in whatever contributes to its coherent and 
THE MORAL CONSIDERABILITY OF HOMO SAPIENS

effective functioning as the particular ongoing life-process which it is, with its own particular character' (479).

6. Therefore species have interests (from 4, 5).

7. The interests of a species are not reducible to the aggregated interests of its constituent organisms (479).

8. Therefore Homo sapiens has interests that are not reducible to the aggregated interests of the individual human beings that comprise it (from 6, 7).

\section{Stage Two}

9. Homo sapiens has interests that are not reducible to the interests of its constituent parts, i.e. individual human beings (conclusion of Stage One.)

10. How we treat Homo sapiens is a moral matter (479).

11. Any virtuous person would have concern for the interests of Homo sapiens (484-5).

12. Therefore Homo sapiens, or if you prefer, the interests of Homo sapiens, are morally considerable (from 9-11).

\section{Stage Three}

13. Homo sapiens, or if you prefer, the interests of Homo sapiens, are morally considerable (conclusion of Stage Two).

14. '...what we do now, individually and collectively, has an impact on the future sections of the Homo sapiens life-process' (479).

15. Indeterminate future parts of an existing morally considerable entity should be the object of moral concern (478-9).

16. Future generations of human individuals are the future parts of Homo sapiens (478).

17. Therefore future generations of human individuals should be the object of moral concern (from 13-16).

This is an ambitious argument. ${ }^{3}$ If successful it would establish the moral considerability of Homo sapiens (as well as, by straightforward extension, all other species) and provide a basis for concern for future generations. However, there are several difficulties with the argument, some of which will generalise to other attempts to establish the moral considerability of Homo sapiens and other species. 


\section{STAGE ONE: DO SPECIES HAVE INTERESTS?}

In order to justify the claim that Homo sapiens has interests, Johnson starts with the thesis popular among contemporary philosophers of biology (Hull 1976, 1978; Ghiselin 1974, 1997) that species are individuals. According to this view, a species is ontologically the same type of entity as an organism. A species is not a class consisting of organisms as members, but a concrete, particular, persisting object, whose constituent organisms are its parts rather than its members (Crane 2004).

As a strategy for grounding species interests (particularly morally considerable ones), adopting the species-as-individuals thesis is appealing since we are already familiar with some individuals - viz. humans - that have morally considerable interests. It is also an attractive thesis in its own right, ${ }^{4}$ and thus we accept Johnson's first premise, which just is the species-as-individuals-thesis. The project of establishing the moral considerability of species, given that species are individuals, is to determine what features of individuals ground morally considerable interests and to show that species have those features. The mere fact that species belong to the ontological category of 'concrete, particular, persisting things comprised of material parts' is clearly insufficient to ground morally considerable interests. If it were sufficient, Styrofoam cups, rocks, and pretzels would be morally considerable entities.

What Johnson adds in his attempt to grant moral considerability to species is that species are living processes. Johnson's Premise 5 asserts that it is this feature that grounds the interests of an individual, whether a whole species or an individual human. Yet Johnson's argument that species are living processes is unpersuasive, even granting that species are individuals. To show this we begin with Premise 2 - the claim that a species is a living entity - before turning our attention to Premise 3 - the claim that a living entity is an ongoing process.

Proponents of the species-as-individuals thesis are careful to point out that they do not claim that species are organisms (Ghiselin 1997: Ch 3-4; Hull 1976). Species are thought to be less cohesive than organisms - they are less dependent for their continued existence on the integration and coordinated functioning of their parts. In addition, species are not limited in their development by an unchanging genotype - the gene pool of a species may change significantly over time, allowing the species to evolve in indefinitely and unpredictably many ways. Given these significant differences between species and organisms, one should be cautious when claiming that species are living entities, since a living entity is typically thought to be an organism. Of course, there is a sense in which it is almost trivial that a species is a living entity, since a species is composed of living organisms. But this sense of 'living' is too thin to ground interests that are not reducible to the interests of the parts of a living entity. Johnson therefore attempts to develop a more robust account of 'living' that will both ground interests, and apply to species. 
THE MORAL CONSIDERABILITY OF HOMO SAPIENS

Johnson starts with Margulis and Sagan's (1995) account of life as a chemical process, from which he develops his own account of a living entity:

A living entity is an ongoing process, occurring in a dissipative thermodynamically open system, organising and maintaining itself in near equilibrium with its environment by means of high levels of homeorhetic feedback sub-systems (479).

Johnson asserts that this characterisation of life is satisfied by species as well as organisms. Is this true? A thermodynamically open system, Johnson tells us, is 'one which admits of an in- or outflow of energy in some form, such as matter, light, or heat' (485). Unlike thermodynamically closed systems, which tend toward disorder (an increase of entropy), a living entity maintains high levels of order. This is a plausible characterisation of organisms. Yet even if organisms are thermodynamically open systems, it does not follow that a species composed of organisms as parts is also thermodynamically open. Species, being less cohesive, are less organised and orderly. Moreover, the tendency of the evolutionary process seems to be toward increasing biodiversity. Even within the span of a few generations of a sexually reproducing species, there may be a marked increased in diversity of genotypes. The evolutionary tendency toward increasing diversity of genotypes and the comparative lack of cohesion suggest that species are at best less thermodynamically open than organisms.

Does a species organise and maintain itself 'in near equilibrium with its environment by means of high levels of homeorhetic feedback sub-systems'? 'Homeorhetic,' Johnson tells us, is meant to capture the idea that life 'maintains itself within a favourable range of states, but does not continually maintain constant states' (485). That is, living things do not maintain constant homeostasis with their environment, but are somewhat more variable. However, species are not limited as organisms are to states allowable within a fixed genotype. Not only do they not maintain constant states; since a species can evolve in indefinitely and unpredictably many ways, it is not confined to a limited range of states. Johnson may have in mind here that species often persist within certain parameters, filling certain roles in ecosystems, at least for a period of time. ${ }^{5}$ But a species may also persist when it undergoes significant adaptations such that it does not maintain itself within a fixed range of states - even if 'states' is understood in terms of ecosystemic role, since species sometimes overrun or transform the ecosystem of which they are part. To suppose that species are confined to a range of states, and persist as 'living entities' so long as they maintain themselves within these parameters, is to suppose a static species concept of the sort that evolutionary theory makes untenable. Indeed, part of the motivation for thinking that species are individuals is the idea that species can no longer be thought of as unchanging types, but are historical entities that change due to evolutionary pressures (Hull 1978). 


\section{RONALD SANDLER AND JUDITH CRANE}

Given these considerations, the best case that can be made for assimilating species into Johnson's characterisation of life will start by recognising that being a living thing on this account may be a matter of degree. Individuals are more or less cohesive, organised, and structured. If a compelling case can be made that species are living entities, they are less so than organisms. ${ }^{6}$ The crucial question is whether species are 'living' to an extent and in respects that ground morally considerable interests. The worry is that in making the claim that species are living entities metaphysically and biologically respectable by providing an account of 'living entity' that is appropriately applied to them, one must adopt a conception of 'living entity' on which it is tenuous that all living entities have interests. The category becomes inclusive of things that fall far below the level of organisation and cohesion that we regularly identify with the paradigm of living things with interests: organisms. The fact that species are living (on a sufficiently liberal definition) is thus doing no real work toward establishing that they have interests. The real question is whether something as loosely aggregated in terms of cohesion and organisation as species can have interests. Fiddling with the definition of 'living' is not going to resolve that question.

Premise 3 - that a living entity is an ongoing process - is also potentially problematic. Given an account of life as a process, is there any reason to think a living entity is a process? We should be clear about what it means to say an entity is a process. Processes have a temporal dimension. They are temporally extended, consist of temporal stages, and are typically described as four-dimensional. It is more controversial that a persisting object - a human being or a species understood as an individual - is four-dimensional. It is not a consequence of the claim that species are individuals that they are four-dimensional. ${ }^{7}$ A threedimensional persisting object, say a human being, can be the locus of numerous events and processes in virtue of which it is alive. So we can accept that life is a process, without claiming that living entities are processes.

However, Johnson does not need 3 or the inference to 4 to show that species have interests. Being a process is not necessary to having interests; what is required is being a persisting thing. Having interests requires the possibility of concern for one's future and past states, which is possible only for a thing that persists over time. Both three- and four-dimensional objects can persist, but they differ with respect to how they persist. Species can be understood as three-dimensional enduring objects, existing wholly in different times and places and undergoing continual change of parts (their constituent organisms), or as four-dimensional perduring objects, which are spread out in time, and consist of temporal as well as spatial parts. If species are individuals it is their persistence that is relevant to their having interests, whether they are three- or four-dimensional. The upshot of this for Johnson's argument is that Premise 5 - which is central to his argument that species have interests and presupposes that living entities are processes - is inadequately supported, but also unnecessary as formulated. Johnson could substitute a metaphysically neutral version: 
THE MORAL CONSIDERABILITY OF HOMO SAPIENS

$5^{*}$. A living, persisting entity has an interest in whatever contributes to its coherent and effective functioning as the particular entity that it is, with its own particular character.

Although $5^{*}$ is more attractive for grounding species interests than 5 - since it will not require the questionable transitional premise that species are processes - it will require making sense of the 'particular character' and 'interests' of a species. Presumably, the 'particular character' of a given species informs what it has an interest in maintaining or promoting, such that when filled into the blank in 'Species X has an interest in __, we get a true statement. Any attempt to establish that species have interests must provide something here, or else talk of the interests of species will be empty. ${ }^{8}$

It is not obvious how the blank should be filled for a given species. Perhaps we are to consider all the features of the individual species to ascertain its character. At any time a species will consist of a number of organisms bearing certain biological relations to each other (parent/offspring, potential mate, competitor), and a certain distribution of genetic and phenotypic traits across populations of those organisms. However, the organisms that comprise the species, the distribution of traits, and the population size will change from one generation to the next. Further, as emphasised above, over time a species can change in indefinitely and unpredictably many ways. Indeed, if a species is not to go extinct, it must adapt to environmental changes (even those it causes). It is therefore not always in the interest of a species that it maintain its character, if its character is understood as a particular range of distributions of genetic and phenotypic traits or population sizes.

A more promising suggestion is that the relevant 'particular character' of a living entity is its character as a particular kind of living thing. The "coherent and effective functioning' of a living entity is its proper functioning or living well as a human being, or as a sand-hill crane, or as a species. To the extent that Canis lupus is a living entity, what counts as its proper functioning as a species depends on the kind of living entity a species is. Species are less cohesive than organisms, so their proper functioning does not involve maintaining the level of organisation that organisms maintain. Species are entities made up of organisms bearing certain biological relations to each other; species propagate themselves and adapt to environmental changes. Functioning well as a species would therefore seem to involve nothing more than maintaining populations of reproducing organisms, propagating itself, and adapting to evolutionary pressures. The better a species functions, the larger its population size, the longer it lasts, and the more pliable it is. Thus if species have interests, the interests of any particular species would seem to consist in whatever contributes to its functioning well so understood. ${ }^{9}$ 
RONALD SANDLER AND JUDITH CRANE

\section{STAGE TWO: ARE THE INTERESTS OF SPECIES MORALLY CONSIDERABLE?}

Let us suppose the Stage One argument is sound and establishes that Homo sapiens has interests that are not reducible to the interests of its constituent parts. The Stage Two argument is intended to show that the interests of the species are morally considerable. It is tempting to infer directly from ' $\mathrm{X}$ has interests' to 'X is morally considerable.' But Paul Taylor (1986: Ch 2) has shown that possessing interests (in Taylor's terms, 'a good of one's own') is necessary but not sufficient for being morally considerable. The question, 'does the oak tree in my backyard have interests?' and the question, 'should the interests of the oak in my backyard be of concern to me?' are distinct. An affirmative answer to the first is necessary but insufficient for an affirmative answer to the second. The challenge here, like the problems that arise in attempting to establish species as living things with interests, does not arise because of something peculiar to Johnson's argument. Any attempt to establish the moral considerability of Homo sapiens from the claim that it has interests must provide an argument for the moral considerability of those interests.

Johnson appeals to three considerations in his attempt to show that the interests of Homo sapiens are morally considerable. The first is that "how we affect others is subject to moral assessment' (479), whereas how a person treats herself is a matter of prudence. But this begs the question. The issue just is whether we ought to be concerned about the interests of the individual Homo sapiens. Since the matter is unresolved, claiming that how we treat Homo sapiens is a matter of moral assessment is merely to assert that we ought to be concerned about its interests. But asserting that we should be so concerned is not to give reasons for being concerned.

Johnson's second consideration is that 'we individual humans have interests, morally considerable ones, which do not and may never impinge on our consciousness... [and]... it is true that, biologically, we evolved consciousness to serve our interests, rather than developed interests because we have consciousness' (479). This claim also begs the question. We humans do have interests that may properly be described as non-conscious, and those interests are often morally considerable. But our interests must be considered because we are morally considerable individuals. If an individual is morally considerable, some of its non-conscious interests must be considered. It follows that if species are morally considerable, their non-conscious interests must be considered. However, this does not establish that species (including Homo sapiens) are morally considerable individuals. It just shows what would be the case if they were. We are still left without an argument to establish that Homo sapiens, or if you prefer, the interests of Homo sapiens, are morally considerable.

A third aspect of Johnson's argument that may be an attempt to fill this gap is his appeal to virtue ethics. He believes that we cannot look to act-centred 
theories such as utilitarianism and Kantianism to establish that we ought to be concerned with the interests of Homo sapiens. We must instead look to an ethic of character. The answer to the question 'why should we be concerned with the interests of Homo sapiens?' is that absence of such concern betrays a lack of virtue. The challenge for this approach is to identify the virtues that would be offended by a lack of concern for Homo sapiens.

Johnson advocates a naturalistic approach to the specification of virtue. He believes it is a matter of contingent naturalistic fact that we are constituted so that we flourish only if we have certain character traits. Examples of these traits include dispositions that are life-affirming and promote social cooperation. Such dispositions are virtues because 'it is virtually undeniable that it is characteristic of humans to desire human company and to value good relations with other people...Misanthropy certainly is a symptom of poor health of character. Little healthier is callousness. An attitude of openness toward and affirmation of other human life is a much healthier sign' (484). ${ }^{10}$ This much of Johnson's account seems to us correct. Naturalistic considerations must be part of the specification of virtue, since such considerations are essential to understanding what it is to flourish as a human being. Even if one does not accept a strictly eudemonistic approach to the specification of the virtues - one that recognises only consideration of agent flourishing as relevant - certainly it is part of the story. ${ }^{11}$

But as Johnson recognises, establishing that the virtuous person will be disposed to consider the interests of other individual humans is not sufficient to establish that she will be disposed to consider the interests of Homo sapiens. So 'what of humanity as a whole?' (484). Johnson offers the following:

For myself, I would speculate that indifference to the future prospects of the human life-process of which we are a part is a sign of a not fully healthy character. I can offer no rules, utilitarian or deontological, for how we are properly to treat the interests of individuals and humanity. I doubt that it can be a matter of rules. What it can be is a matter of attitude, a matter of respect for and affirmation of the quality and richness of life (484, his emphasis).

Johnson seems to be suggesting that the operative virtue is respect for life, and for its 'quality and richness'. As we believe there are compelling arguments in favour of a virtue of respect for life, ${ }^{12}$ we find this to be the most promising way to give substance to Johnson's speculation. Can such a virtue ground the moral considerability of Homo sapiens?

As discussed above, it is at best controversial whether, and to what extent, Homo sapiens is 'living'. This difficulty is relevant here because the more liberal the sense of 'living' that must be adopted to include species, the less plausible the suggestion that it is part of good character that we have respect for all life. Moreover, even supposing Homo sapiens has a life worthy of respect, it is not clear what the 'quality and richness' of that life consists in. Since Homo sapiens does not have mental states, its life does not have a phenomenological quality 
or richness. What then is it about the 'life' of Homo sapiens (or any other species) that merits our respect? Is it the maintenance of organisation that we are to respect? Or whatever its particular interests are? Even if we accept this, respect for life will at best provide Homo sapiens with moral standing equivalent to that of any other living thing qua living thing, in the inclusive sense. As will be shown in the next section, this will not have the implications regarding the problem of future generations that Johnson is aiming for.

\section{STAGE THREE: WHAT WOULD BE THE IMPLICATIONS OF THE MORAL CONSIDERABILITY OF SPECIES?}

Let us now suppose the first two stages of the argument are sound and establish that Homo sapiens is morally considerable. Johnson believes that establishing the moral considerability of Homo sapiens can ground concern for the interests of future generations of humans. The problem of future generations is the difficulty of accounting for moral obligations, duties, or even concern for individuals that constitute future generations. ${ }^{13}$ The difficulty arises because the individuals that constitute future generations both do not currently exist and are indeterminate. Compounding the difficulty is that part of the contingency or indeterminacy of the make-up of future generations rests on our actions. What we do now affects who will exist later. The upshot of these facts about future generations is that it is difficult to make sense of how we could possibly wrong them. One way to see this is in light of the Person Affecting Principle (PAP):

Only acts which affect or can reasonably be expected to affect (i.e. benefit or harm) the ongoing lives of particular individuals can count as morally significant (Partridge 2002).

Since future generations do not now exist and their constitution is determined in part by acts we perform prior to their existence, it is never the case that what we do now makes any particular person in a future generation worse off. After all, if we do not perform the act they will not exist. ${ }^{14}$

Johnson believes that recognition of the moral considerability of the interests of Homo sapiens is the key to resolving the problem of future generations: the moral considerability of Homo sapiens grounds obligations to future generations and the currently indeterminate human beings that will constitute them. ${ }^{15}$ But why would consideration of the interests of a species involve equal concern, or concern at all, for each of its future parts? Perhaps sacrificing the quality of some future part for a current part or for other future parts is justified. Do not humans do this with parts of their lives in the service of others, or parts of their bodies? Addressing these questions would require giving an account of what the interests of a species are. We argued in the Stage One discussion that the most plausible understanding of species interests is in terms of longevity, 
THE MORAL CONSIDERABILITY OF HOMO SAPIENS

population size, and adaptability. But construing the interests of Homo sapiens this way does not imply concern for the welfare of all (or even most) future individual human beings.

Perhaps it is in the interest of a species to have its parts flourish in a certain way - quality matters, not just quantity or duration. This seems to be what Johnson is after when he writes about protecting 'the long-term quality of human life' (482). But how would we measure quality regarding the parts of a species if not quantitatively or in terms of how the parts contribute to the longevity or adaptability of the species? It will not do to appeal to the quality of life of the indeterminate individuals that will constitute future parts of the now existing species, since these individuals are morally considerable only insofar as they allow the species to flourish; and just what that means is at issue. Moreover, what it is for a particular member of a species to flourish will not be the same as what it is for the species itself to flourish. Flourishing for a particular wolf is very different from the flourishing of Canis lupus. Canis lupus is not sentient, social, or sexually reproductive. Its flourishing does not involve running in a pack, copying its genetic material, or avoiding bodily injury. It is important to resist conflating the flourishing and interests of a species with the flourishing and interests of its parts. ${ }^{16}$

Without an argument for why the interests of a species involve the flourishing of its future parts, the most the approach shows, given the moral considerability of Homo sapiens, is that it might be rational to be concerned for the welfare of indeterminate future humans. To show that such concern is required one must provide an account of the interests of Homo sapiens that involves, necessarily, the flourishing of its now indeterminate future parts. We are doubtful that this can be established. Supposing an individual human being is morally considerable, it does not follow that others should have concern for the welfare of the (currently indeterminate) particular cells that will make her up in the future. But that is just the status of future (indeterminate) individual humans in relation to Homo sapiens.

It will not help to appeal to the quality of future generations, rather than future individual human beings, since a future generation is simply the collection of individual members of the species living at a particular future time. Even if we understand future generations to be ontologically extra to their members, what would their flourishing consist in? What would be a qualitative account of their interests? Why think it would involve the flourishing of the individual human beings that constitute them? Rather than explaining why concern for the interests of Homo sapiens requires concern for future individual human beings, appeals to future generations as distinct entities will raise all the same sorts of questions. So even granting that Homo sapiens is morally considerable, it is not obvious what obligations, duties, or concern that would justify, and whether it would remedy or exacerbate the problem of future generations. 


\section{RONALD SANDLER AND JUDITH CRANE}

Moreover, even if all of our concerns with the three-stage argument were addressed and it were established that Homo sapiens is a morally considerable entity whose future parts are thereby morally considerable, this would still not provide a satisfactory resolution to the problem of future generations. The argument, if successful, would be applicable to all other species, mutatis mutandis. It would establish that all species are equally morally considerable, and that all future individual organisms (or generations) of all species are equally morally considerable. There is nothing in the argument that appeals to any special property of Homo sapiens to establish its moral considerability. If Homo sapiens is morally considerable, then so is Canis lupus, E. coli, and so on. Furthermore, future indeterminate parts of Homo sapiens are morally considerable only in virtue of their relationship to the interests of their species. There is nothing about them, or the kind of individual organism they are, that makes them morally considerable. But each future individual organism of every species has an analogous relationship with the individual that is its species. Since all species are as morally considerable as Homo sapiens and the relationship between each future individual organism and its species is also the same, all future individual organisms are as morally considerable as every future individual human. Each future individual bacterium, wolf, and stinging nettle is as considerable as each future individual human. No appeal to the special, unique, characteristic, or differential properties of individual humans will resolve this problem, since it is no intrinsic property of them that makes them morally considerable, only their status as future parts of an existing morally considerable individual. Because there are perhaps trillions of species and current and future individual organisms, the interests of Homo sapiens (and thus concern for future generations of humans) are likely to be overwhelmed on nearly all occasions by consideration for the interests of other living individuals.

One response to this criticism might be that upon a more complete specification of human excellence we will find that a virtuous person will be concerned about Homo sapiens and its constituents in a way or to a degree that she is not concerned about the interests of other species and their constituents. But we have just seen that there is nothing in the virtue of respect for life that provides for such distinctions, so any extra concern for Homo sapiens would have to be based on something other than its status as a living thing. We have no plausible suggestions regarding what this basis and the corresponding virtue might be.

\section{CONCLUSION}

The upshot of these considerations is that it has not been established that (1) Homo sapiens is a living entity, (2) Homo sapiens has interests, (3) those interests are morally considerable, and (4) those interests include the living well of indeterminate future generations of the species. In addition, even if all that 
were established, it would not alleviate the problem of future generations. We have focused at length on Johnson's argument because it makes several claims that are likely to be part of any attempt to establish the moral considerability of species in general, and Homo sapiens in particular: that species are individuals, that they are living individuals, that they have interests distinct from the individual organisms that constitute them, and that we ought to be concerned with those interests. We have seen that several of these claims - both individually and in combination - are problematic, and that when made plausible there remains the problem of showing precisely what the interests of species actually consist in or what appropriate consideration of their interests would amount to. Moreover, we have argued that whatever the interests of species actually consist in, the moral considerability appropriate to species (including Homo sapiens) as living individuals with interests would not provide robust normative or practical implications.

\section{NOTES}

The authors would like to thank Philip Cafaro and Berit Brogaard for their helpful comments and suggestions on an earlier version of this paper.

${ }^{1}$ Johnson $(1983 ; 2001)$ argues for the moral considerability of species generally. Norton (1991) also advocates obligations to Homo sapiens as a response to the problem of future generations. His 'Axiom of Future Value' states that 'The continuance and thriving of the human species (and its evolutionary successors) is a good thing, and every generation is obliged to do what is necessary to perpetuate that good. The obligation to perpetuate and protect the human species is therefore accepted as a fundamental moral axiom, which exists independently of obligations to individuals' (216). Sterba $(1995 ; 2001)$ has endorsed the status of species, including our own, as moral patients. Those who have objected to the moral considerability of species include Sober (1986), Russow (1981), and Taylor (1986: Ch. 2, n.5).

${ }^{2}$ Johnson does not present his argument as proceeding in three distinct stages. We have presented it this way for clarity and usefulness in organising discussion. This reconstruction deviates from the order of Johnson's presentation in that Johnson does not appeal to virtue ethics to justify the move from 'the interests of Homo sapiens can be the object of moral concern' to 'the interest of Homo sapiens should be the object of moral concern' until the end of his paper, whereas we have included in the middle of the argument (Premise Eleven). As a result, prescriptive language appears earlier in our reconstruction than it does in his presentation.

${ }^{3}$ Johnson (1991: Ch. 3-4, 6) provides essentially the same argument, albeit in more detail.

${ }^{4}$ Crane (2004) argues that species concepts (concepts that give criteria for conspecificity) have implications for the ontological status of species, and that certain species concepts do entail that species are individuals. Notably, Mayr's biological species concept ('a species is a group of interbreeding natural populations that is reproductively isolated 


\section{RONALD SANDLER AND JUDITH CRANE}

from other such groups,' 1991: 26), which is widely (though not universally) accepted, plausible in light of our best biology, and theoretically powerful, entails that species are individuals.

${ }^{5}$ Johnson (1991: 158, 161, 178, 180, 210) suggests this.

${ }^{6}$ It is sometimes maintained that since there are degrees of cohesiveness, being an individual is itself a matter of degree, and that species are individuals to a lesser extent than, say, organisms (Ereshefsky 1991; Sober 2000). Crane (2004) argues that while individuals may be more or less cohesive, individuality does not come in degrees. Johnson's account of 'living' can be a matter of degree whether or not individuality comes in degrees.

${ }^{7}$ Crane (2004) argues that the species-as-individuals thesis is compatible with both three- and four-dimensional interpretations. Most of the literature on species-as-individuals does not address the issue. An exception is Hull (1989), who maintains species are four-dimensional.

${ }^{8}$ Johnson (1991: Chs 4, 6) makes several claims about what the interests of species are: to persist, to persist as the life process that it is, to maximise its number of living descendents, to maintain its genetic diversity, to maintain a functional equilibrium between itself and its environment, to fulfil its nature as a species, and to fulfil its nature in its individual species members. We consider each of these over the course of this paper.

${ }^{9}$ The general strategy here is to identify the relevant kind to which an individual belongs and then the standard for determining to what extent a member of that kind is flourishing. We have taken the relevant kind to be species and the relevant properties to be longevity, population size, and adaptability. These are, we believe, the most plausible in light of our best biology and metaphysics, as well as the most promising when it comes to trying to show that the interests of species are morally considerable. Other kinds one might be tempted to employ - constituents of ecosystems, metaphysically distinct individuals - are too general to be kinds of living things, even liberally understood.

${ }^{10}$ Johnson (2003) also writes, 'it is a contingent truth about us as humans, a fact which might have been otherwise, that to have [a strong, whole, healthy, well-functioning] character we must have the attribute of being life-affirming' (484).

${ }^{11}$ Hursthouse (1999: Ch 8-10) advocates a naturalistic and strictly eudemonistic approach to specifying the virtues. Foot (2001) advances a similar approach. Swanton (2003: Ch 4), while accepting naturalistic and eudemonistic considerations as relevant to the specification of virtue, has argued for a more inclusive and pluralistic approach.

${ }^{12}$ Such a virtue has been advocated by Taylor (1986) and Sterba (1995; 2001).

${ }^{13}$ A detailed description of the problem can be found in Johnson (2003: 472-477). Johnson approaches the problem through the dialogue between Carter $(2001 ; 2002)$ and Partridge (2002). Also relevant are Parfit (1982; 1984).

${ }^{14}$ This formulation of the problem assumes that any act we perform will have sufficiently broad repercussions that the act will affect all members of sufficiently distant (temporally) future generations. This is the Strong Butterfly Effect principle, which Johnson accepts (2003: 474). Carter, however, rejects it. He writes, 'it is absurd to think that anyone has the power through every one of his or her environmentally destructive activities to determine the coming into existence of every future person' (2001: 442). Carter favours the Weak Butterfly Effect principle: the repercussions of the collection of actions performed by a generation as a whole are sufficiently broad that they will affect all members of sufficiently distant (temporally) future generations, but the repercussions of the action 


\section{THE MORAL CONSIDERABILITY OF HOMO SAPIENS}

of any particular member of a generation are not so robust as to affect all members of sufficiently distant (temporally) future generations. On the WBP it is possible for an individual in the present generation to make individuals in future generations worse off. So, Carter insists, the best way to avoid the future generation paradox is 'to avoid being mesmerised by collectives' (2001: 444). The disagreement between Johnson and Carter is an empirical one, concerning the breadth and depth of the effects of certain events. For present purposes, we are following Johnson because it is his argument that concerns us. Even if Carter is correct about the empirical question, we agree with Johnson (2003: 474) that there is still a compelling moral question: would we be 'morally free, were no specific individuals at all to be affected, to act as we pleased with regard to future generations?'

${ }^{15} \mathrm{He}$ also argues for this claim in Johnson 1991: Ch 4.

${ }^{16}$ In other writings Johnson appears to conflate these: 'A species has an interest in ... fulfilling its nature in its individual species members' (1991: 178).

\section{REFERENCES}

Carter, Alan. 2001. 'Can We Harm Future People?', Environmental Values, 10(4): 439-54.

Carter, Alan. 2002. 'On Harming Others: A Response to Partridge', Environmental Values, 11(1): 87-96.

Crane, Judith. 2004. 'On the Metaphysics of Species', Philosophy of Science, 71(2): 156-73.

Ereshefsky, Marc. 1991. 'Species, Higher Taxa, and the Units of Evolution', Philosophy of Science 58(1): 84-101.

Foot, Philippa. 2001. Natural Goodness. Oxford: Oxford University Press.

Ghiselin, Michael. 1974. 'A Radical Solution to the Species Problem', Systematic Zoology, 23(4): 536-44.

Ghiselin, Michael. 1997. Metaphysics and the Origin of Species. Albany: SUNY Press.

Hull, David. 1976. 'Are Species Really Individuals?', Systematic Zoology, 25(2): 174-91.

Hull, David. 1978. ‘A Matter of Individuality', Philosophy of Science, 45(3): 335-60.

Hull, David. 1989. The Metaphysics of Evolution. Albany: State University of New York Press.

Hursthouse, Rosalind. 1999. On Virtue Ethics. Oxford: Oxford University Press.

Johnson, Lawrence. 1983. 'Humanity, Holism, and Environmental Ethics', Environmental Ethics, 5(4): 345-54.

Johnson, Lawrence. 1991. A Morally Deep World. Cambridge: Cambridge University Press.

Johnson, Lawrence. 2003. 'Future Generations and Contemporary Ethics', Environmental Values, 12(4): 471-87. 
16

\section{RONALD SANDLER AND JUDITH CRANE}

Margulis, Lynn, and Dorion Sagan. 1995. What is Life? New York: Simon and Schuster.

Mayr, Ernst, and Peter D. Ashlock. 1991. Principles of Systematic Zoology, 2nd edn. New York: McGraw-Hill.

Norton, Bryan. 1991. Towards Unity Among Environmentalists. Oxford: Oxford University Press.

Parfit, Derek. 1982. 'Future Generations: Further Problems', Philosophy and Public Affairs, 11(2): 113-72.

Parfit, Derek. 1984. Reasons and Persons. Oxford: Oxford University Press.

Partridge, Ernest. 2002. 'The Future - For Better or Worse', Environmental Values, 11(1): $75-85$.

Russow, Lilly-Marlene. 1981. 'Why do Species Matter?', Environmental Ethics, 3(2): 101-12.

Sober, Elliot. 1986. 'Philosophical Problems for Environmentalism', in B. Norton (ed.), The Preservation of Species (Princeton: Princeton University Press), pp.173-94.

Sober, Elliot. 2000. Philosophy of Biology, 2nd edn. Boulder: Westview Press.

Sterba, James. 1995. 'From Biocentric Individualism to Biocentric Pluralism', Environmental Ethics, 17(2): 191-207.

Sterba, James. 2001. Three Challenges to Ethics: Environmentalism, Feminism, and Multiculturalism. Oxford: Oxford University Press.

Swanton, Christine. 2003. Virtue Ethics: A Pluralistic View. Oxford: Oxford University Press.

Taylor, Paul. 1986. Respect for Nature: A Theory of Environmental Ethics. Princeton: Princeton University Press. 